\title{
Outdoor Education Of Emphathy Student
}

\author{
Budiman $^{1)}$, Ruslan Rusmana ${ }^{2)}$, Lingling Usli Wargadinata ${ }^{3)}$ \\ Program studi Pendidikan Jasmani Kesehatan dan Rekreasi \\ Jurusan Pendidikan Olahraga \\ ${ }^{1,2,3}$ STKIP Pasundan, Kota Cimahi, Jawa Barat, Indonesia \\ Email: ${ }^{1}$ budiman@ stkippasundan.ac.id, ${ }^{2}$ ruslanrusmana@ stkippasundan.ac.id, \\ ${ }^{3}$ linglingpikrstkippasundan@gmail.com
}

\begin{abstract}
The essence of the research studies that researchers carried out were to obtain data and research on the impact of outdoor education on student empathy. This method uses an experimental method while the village uses a randomized control group test pre-test final design. The population is students of class VIII Junior High School III Bayongbong with a total of two hundred and six (206) people. Sixty samples were taken, selected using a random sampling technique. These random results, obtained thirty samples of the experimental group and thirty samples of the control team. The measuring instrument used in measuring empathy behavior uses an empathy scale test that has been tested for its validity and reliability. In calculating the hypothesis testing statistics using the SPSS 23 application through paired t-test Paired sample t test. The final data from the results of data analysis can be seen that outdoor activities have an influence on empathy behavior. The results obtained are Sig.2tailed 0, 000 < $<0,05$. From the results of data processing and analysis, it can be ignored that outdoor education has a significant effect on student empathy.
\end{abstract}

Keywords: Outdoor Education, Empathy, Students

\section{PENDIDIKAN OUTDOOR TERHADAP EMPATI MURID} ABSTRAK

Inti dari kajian penelitian ini dilaksanakan untuk memperoleh data serta menguji dampak pendidikan luar ruangan terhadap empati murid. Metode ini menggunakan metode eksperimen adapun desainnnya dengan menggunakan randomized control grup test awal-test akhir desain. Populasinya adalah murid kelas VIII Sekolah Menengah Pertama III Bayongbong dengan jumlah dua ratus enam (206) orang. Sampling yang diambil berjumlah enam puluh orang dipilih dengan menggunakan teknik sample secara acak. Hasil cara acak tersebut, didapat tiga puluh sampel regu eksperimen dan tiga puluh sampel regu kontrol. Alat ukur yang dipakai dalam mengukur prilaku empati yaitu memakai test skala empati yang sudah diuji validitas serta realibilitasnya. Dalam menghitung statistik pengujian hipotesis menggunakan aplikasi SPSS 23 melalui uji-t berpasangan Paired sampel $t$ test. Data ahir hasil analisis data dapat dilihat bahwa aktivitas luar ruangan ada pengaruh pada prilaku empati murid diperoleh hasil Sig.2tailed 0, $000<\alpha 0$, 05. Dari pengujian tersebut hasil pengolahan dan analisis data, maka dapat disimpulkan Outdoor Education memberikan pengaruh yang signifikan terhadap empati murid.

Kata Kunci: Pendidikan Outdoor, Empati, Murid

Info Artikel

Dikirim

Diterima

Dipublikasikan
: 3 Agustus 2020

: 4 November 2020

: 12 November 2020 


\section{PENDAHULUAN}

Soft Skill merupakan bagian dari salah satu bentuk kecakapan hidup yang wajib dimiliki setiap orang sebagai makhluk sosial. Pada dasarnya soft skill adalah keahlian seseorang agar dapat berkomunikasi secara efektif dengan siapapun. Dalam dunia pendidikan, seorang pendidik perlu memperhatikan proses pendidikan yang dialami murid dengan membekali berbagai kecakapan hidup termasuk keterampilan sosial agar murid dipersiapkan menjadi manusia masa depan seutuhnya yang berkualitas dan unggul serta siap menghadapi perubahan kehidupan yang semakin cepat dan kompleks. Ciri murid yang punya soft skill biasanya lebih berani berbicara, mengungkapakan perasan, masalah yang dimiliki dan sekaligus memberikan solusi masalah yang adaptif. Selain itu, soft skill akan membawa murid memiliki sikap yang baik yang diharapakan, seperti sikap ramah tamah, tolong menolong, kerja sama dan juga empati. Salah satu cara memiliki sikap keterampilan bisa dilakukan melauli aktivitas Penjas karena Penjas dikatakan sebagai bagian integral atau tidak bisa dipisahkan dari pendidikan lainnya. Penjas berisi pengembangan aspek kebugaran jasmani, movement skill, kongnitif, emosional, keterampilan dan perilaku sikap lewat kegiatan atau aktivitas olahraga yang disusun sedemikian rupa dengan tersusun yang yang bermaksud untuk dapat meningkatkan individu secara jasmani, kongnitif, sosial, dan emosional. (Yulingga Nanda Hanief, 2015).

Tindakan yang mengindikasikan rendahnya empati murid terlihat dari tindakan kekerasan yang semakin marak dilakukan dikalangan murid. Tindakan tersebut terbaca dari berita yang diberitakan Sindo.News (Wahyu Sikumbang, 2015) yaitu Rivo tewas setelah sebelumnya diduga dipukul teman sekelasnya (MA). Rivo dituduh mencuri pulpen pelaku (MA). Rivo sempat mendapat perawatan di rumah sakit sebelum meninggal dunia. "Selain itu, ada lagi kekerasan verbal dan psikis melalui tindakan bullying, yang kerap dilakukan oleh murid, sehingga berdampak pada psikis murid yang menerima perlakuan. Dalam sebuah berita harian merdeka.com (Nugroho, 2015). Seorang siswi kelas V di SDN Bintara 2, Kecamatan Bekasi Barat, Kota Bekasi, menjadi korban bully oleh teman-temannya. Akibatnya, siswi berusia 11 tahun berinisial CA itu enggan bersekolah lagi. Isu di atas mengindikasikan rendahnya keterampilan setiap orang 
untuk memahami perasaan, pikiran dan kondisi orang lain atau rendahnya empati yang dimiliki seseorang tersebut. Orang yang mempunyai empati tidak mungkin melakukan kekerasan hingga melukai perasaan orang lain bahkan sampai tega melakukan tindakan yang merugikan orang lain. Seseorang yang mempunyai empati mampu berdiri pada posisi orang lain, untuk melihat dengan mata, dan merasakan dengan hati.

Empati adalah ciri kepribadian yang memungkinkan seseorang untuk mengidentifikasi situasi, pikiran, atau kondisi orang lain dengan menempatkan diri dalam situasi mereka (Kim, 2020). Pada era yang semakin digital, otomatis, dan terpolarisasi, empati tampaknya ada menurun (Bartelds et al., 2020). Prilaku empati yang dimiliki individu haruslah ditanamkan dalam diri dan dikembangkan agar melekat menjadi identitas individu. Peneliti berpendapat pengalaman pada saat kecil sangat menentukan nasib anak akan seperti apa dimasa depan bahwa pengalaman kejadian masa kecil memberikan kenangan yang abadi kepada individu yang beranjak dewasa sehingga bahwa kejadian masa lalu yang sifatnya sosial serta anti sosial dalam hidup dengan lingkungannya mulai untuk anak sejak usia dini. Hal ini bahwa pembinaan sikap sosial yang baik dari sekarang harus menjadi solusi karena akan teringat secara permanen dan menentukan karakter anak dimasa yang akan datang. Salah satu urgensi yang harus diberikan kepada anak sejak dini adalah sikap empati. That empathy is reduced when humans are emotionally or structurally distanced from the realities of others (Blakemore \& Agllias, 2020). Yang pada intinya bahwa sifat empati akan berkurang manakala manusia secara emosional atau secara struktural menjauhkan dari kehidupan nyata, seharusnya pendidik memperkenalkan kurikulum atau aktivitas yang dalam beberapa cara memberikan kontribusi terhadap perkembangan karakter murid. Sama halnya yang diungkapkan oleh (Meyers et al., 2019) high level of empathy in relationship is probably the strongest factor in bring change and learning. Bahwa tingkat empati yang tinggi dalam hubungan merupakan faktor paling kuat yang membawa perubahan dalam pembelajaran.

Pendidikan jasmani pada dasarnya adalah mata pelajaran sekolah yang menempatkan tubuh sebagai pusat perhatian (Aartun et al., 2020). Pendidikan jasmani dapat berperan dalam meningkatkan empati salah satunya melalui 
kegiatan di alam bebas atau outdoor education. Outdoor education dipercaya memiliki potensi untuk menolong dalam peningkatan environmentally sympathetic attitudes and behavior. Pendidikan alam bebas yang bersifat menyeluruh akan memungkinkan kontribusi positif terhadap kemampuan sosial murid terutama dalam meningkatkan empati. Hal tersebut sesuai dengan salah satu tujuan outdoor education. Tujuan umum dari outdoor education adalah meningkatkan kemampuan masing-masing dan mengembangkan nilai sosial para pesertanya.

Penelitian (Purnamasari, 2019) menunjukkan bahwa berbagai program pendidikan lingkungan (kunjungan lapangan, hiking, perkemahan, kegiatan petualangan) bertujuan untuk mengembangkan hubungan afektif murid dengan lingkungan alam, kepekaan lingkungan mereka, dan perilaku di luar ruangan, serta hubungan sosial mereka, melalui pengalaman pribadi. Selanjutnya (Rahman, 2019) menemukan bahwa, terdapat hubungan signifikan dalam penerapan outdoor education dengan kompetensi social emotional di kelas. Sejalan dengan itu penelitian (Lutfia, 2014) menunjukkan bahwa outbond memiliki dampak positif pada keterampilan sosial, keterampilan interpersonal, kepemimpinan, dan selfesstem. Adapun menurut (Price, 2019) Keterampilan pembelajaran sosial dan emosional (SEL) yang kurang berkembang membatasi kemajuan pendidikan dan menyulitkan anak-anak dan remaja dengan sosial. Maksud dan tujuannya bahwa keterampilan belajar sosial dan emosional (SEL) yang kurang berkembang membatasi kemajuan pendidikan dan mempersulit anak-anak dan anak muda dengan masalah sosial.

Dari hasil-hasil penelitian yang dipaparkan di atas, telah jelas dan meyakinkan bahwa outdoor education memiliki pengaruh yang positif terhadap perilaku sosial murid. Namun, dari beberapa hasil tersebut, masih sangat kurang penelitian tentang pengaruh ataupun hubungan antara outdoor education dan empati. Berdasarkan keadaan tersebut, peneliti tertarik untuk menguji pengaruh outdoor education terhadap empati murid. 


\section{METODE}

Metodologi Penelitian ini menggunakan metode eksperimen. Populasi terdiri dari semua murid kelas VIII SMPN 3 Bayongbong Kabupaten Garut berjumlah enam rombel dengan muridnya berjumlah 206 murid, berjenis kelamin laki-laki $36 \%$ dan perempuan 64\%. Kemudian total sampel penelitian ini sebanyak enam puluh murid dibagi kedalam dua tim, satu tim eksperimen dan satu tim kontrol dengan memakai cara Simple random sampling (Ali Maksum, 2012). Desain yang dipakai ketika melakukan penelitian ini menggunakan Randomize tes awal-tes akhir Control Group Design (Fraenkel, 2011). Instrumen yang digunakan adalah skala empati yang disusun sendiri oleh peneliti, dengan reliabilitas 0.851. Berdasarkan kompenen indikator kognitif dan indikator afektif. Dari tabel panduan untuk menginterpretasi koefisien korelasi (Sugiyono, 2011) nilai 0.851 masuk dalam kategori sangat tinggi yakni berada pada interval koefisien $0.800-1.000$ dengan tingkat hubungan yang tergolong tinggi, hal ini berarti instrumen empati memiliki reliabilitas sangat tinggi. Untuk menganalisis data dalam penelitian ini menggunakan SPSS 23.

\section{HASIL DAN PEMBAHASAN}

Pengolahan hasil penelitian Uji hipotesis menggunakan analisis uji $\mathrm{t}$ melalui SPSS 23 memakai paireed sample tes Uji t menggunakan paired sample tes dipakai untuk mengetahui pengujian menggunakan kriteria hasil:

1. Nilai Signifikansi atau nilai probabilitas $>0,05$, Ho diterima \& Hi ditolak Nilai Signifikansi atau nilai probabilitas < 0, 05, Ho ditolak dan Hi diterima. Hasil perhitungan uji hipotesis data menggunakan uji paired sample test pada kelompok eksperimen dapat dilihat pada tabel 1.1 .

Tabel 1. Uji paired sample test pada kelompok eksperimen

\begin{tabular}{llll}
\hline $\mathrm{T}$ & Sig. (2-tailed) & Keputusan & Kesimpulan \\
\hline 6,76 & \multirow{2}{*}{0,000} & Ho Ditolak & Pengaruh Signifikan \\
5 & & & \\
\hline
\end{tabular}


Dasar pengujian untuk uji pengaruh data adalah berikut ini:

Hipotesis:

a) $\mathrm{H}_{0}=$ Tidak ada Pengaruh signifikan Outdoor education terhadap empati murid

b) $\mathrm{H}_{\mathrm{i}}=$ Terdapat Pengaruh signifikan Outdoor education terhadap empati murid

Berdasarkan output di atas diperoleh nilai Sig. (2-tailed) sebesar 0,000<0,05. Sesuai dasar pengambilan keputusan Paired Samples Test, maka dapat disimpulkan Ho ditolak Hi diterima, yang artinya bahwa terdapat pengaruh signifikan Outdoor education terhadap empati murid.

Hasil perhitungan uji hipotesis memakai Uji Paired Sample Test data pada kelompok eksperimen dapat dilihat pada tabel 2

Tabel 2 Uji. paired sample test pada kelompok kontrol

\begin{tabular}{llll}
\hline $\mathrm{T}$ & Sig. (2-tailed) & Keputusan & Kesimpulan \\
\hline 1,66 & \multirow{2}{*}{0,106} & Ho & Tidak Terdapat \\
9 & & Diterima & Pengaruh Signifikan \\
\hline
\end{tabular}

Dasar pengujian untuk uji pengaruh data:

Hipotesis:

a) $\mathrm{H}_{0}=$ Tidak ada Pengaruh signifikan terhadap kelompok yang tidak diberikan program Outdoor education.

b) Mengambil keputusan dalam Paired Samples Test, maka dapat disimpulkan $\mathrm{Ho}_{\mathrm{i}}=$ Terdapat Pengaruh siginifikan terhadap kelompok yang tidak diberikan program Outdoor education.

dari luaran di atas diperoleh nilai Sig. (2-tailed) sebesar 0,106 > 0,05, dengan demikian sesuai dasar diterima dan Hi ditolak, yang artinya bahwa tidak ada pengaruh signifikan terhadap kelompok yang tidak diberikan program outdoor education.

Hasil perhitungan uji hipotesis menggunakan Independent Samples Tes pada regu eksperimen dapat dilihat pada tabel 3

Berdasarkan output diatas diperoleh nilai Sig. (2- tailed) sebesar 0, $000<$ 0, 05. dari dasar dalam mengambil hasil Paired Sample Tes, maka bisa disimpulkan Ho ditolak Hi diterima, yang maksudnya bahwa terdapat pengaruh signifikan Outdoor education terhadap empati murid. 
Hasil perhitungan uji hipotesis memakai Uji Paired Sample Tes data Salam kelompok eksperimen bisa dilihat seperti pada tabel 3.

Tabel 3 Uji beda gain skor kelompok eksperimen dengan kelompok kontrol

\begin{tabular}{llll}
\hline $\mathrm{T}$ & Sig. (2-tailed) & Keputusan & Kesimpulan \\
\hline $\begin{array}{l}5,07 \\
3\end{array}$ & 0,00 & Ho Ditolak & $\begin{array}{c}\text { Terdapat Perbedaan } \\
\text { Pengaruh }\end{array}$ \\
\hline
\end{tabular}

Hipotesis yang diajukan:

a) $\mathrm{H}_{0}=$ Tidak terdapat perbedaan pengaruh outdoor education antara ratarata empati dalam kelompok eksperimen dengan kelompok kontrol.

b) $\mathrm{Hi}=$ Terdapat beda pengaruh outdoor education diantara rata-rata empati di kelompok kontrol dengan kelompok eksperimen.

Berdasarkan output di atas didapat nilai Sig. (2- tailed) $0,000<0,05$ oleh karena itu sesuai dasar pengambilan keputusan dalam Uji Independent Sample TTest, oleh karena itu dapat dinyatakan Ho ditolak kemudian Hi diterima, Maka terdapat perbedaan pengaruh outdoor education diantara nilai rata-rata empati dalam tim eksperimen dan tim kontrol.

Berdasarkan data hasil dari lapangan dan kajian peneliti di atas, terdapat pengaruh outdoor education terhadap sikap empati murid. Hal tersebut membuktikan bahwa outdoor education mampu meningkatkan sebuah sikap yang akan dikembangkan oleh guru kepada murid dalam sebuah pembelajaran. Pendidikan luar ruangan yaitu kegiatan yang dapat memberi rangsangan kepada fisikal, emposional, mental, dan sosial.

Berbagai penelitian terkini yang dilakukan (Wijayanti, 2017) bahwa nilainilai pendidikan luar sekolah (outdoor education) sebagai landasan/pondasi pembentukan karakter siswa. Bagi para guru Penjas, hendaknya memahami dan menerapkan pendidikan luar sekolah (outdoor education) sebagai salah satu uapaya pembentukan karakter melalui pembelajaran penjas di sekolah. Kemudian (Asep Ramdan Afriyuandi, 2014) mendukung pendapat bahwa outdoor education dapat memberikan peluang untuk mengembangkan kemampuan sosial atau nilai afektif murid, seperti penelitian. Hasil penelitian tersebut menunjukkan bahwa pendidikan luar ruangan dengan program aktivitas berjalan kaki ke alam, 
memanjat, berjelajah di air, dan kemping berpengaruh terhadap kemampuan afektif murid. Selain itu, penelitian (Wang et al., 2006) mengenai pengaruh pelatihan outward bound pada murid perempuan. Hasil dari penelitian tersebut memperlihatkan bahwa kegiatan pendidikan luar ruangan memberikan dampak positif pada peningkatan kemampuan sosial murid.

Dalam pembelajaran di alam bebas murid menemukan tantangantantangan alam yang bervariasi dan cukup sulit, seperti kontur tanah yang tidak beraturan, jalan yang sempit, jalan mendatar, menurun dan menanjak, gunung, lintasan air, disertai angin, gerimis, terik matahari, atau mendung. Sehingga keadaan tersebut cenderung sulit untuk melewatinya dan bertahan di dalamnya. Seperti yang diungkapkan (Kardjono, 2014) lingkungan punya bermacam halangan dan rintangan yang berbeda, seperti jalan sempit, jalan menurun, padang rumput, semak duri, tanah licin, bebatuan, atau lintasan sungai, disertai angin, hujan dan cuaca panas atau dingin. Namun, dengan keadaan tersebut menuntut murid untuk saling tolong menolong atau bekerjasama dalam melewatinya. Hal ini sesuai dengan pendapat (Kardjono, 2014) Penjelajahan di alam bebas yang cukup sulit ini sebaliknya, menuntut kemampuan fisik dan mental, keberanian, kesabaran, kehati-hatian, disiplin, konsentrasi, dan kerjasama antar kelompok.

Empati terdiri dari dua komponen yaitu kognitif dan afektif. Termasuk kedalam kongnitif yaitumemahami perasaan orang lain, kemampuan mengambil perspektif orang lain sedangkan komponen afektif yaitu respon emosional terhadap emosi orang lain. Karakteristik alam yang sulit dan bervariasi membuat para murid saling tolong menolong atau bekerja sama untuk dapat melewatinya. Dengan begitu, penerapan sikap empati dalam penelitian ini dapat mengubah sikap murid, perilaku yang biasa dilakukan murid seperti menertawakan temannya apabila ada yang terjatuh atau melakukan kesalahan dalam pembelajaran, mengolok-olok teman dan perilaku negatif lainnya telah berubah dengan adanya penerapan sikap empati yang dikembangkan dalam pembelajaran di alam bebas atau outdoor education yang mereka lakukan. Hal ini dibuktikan dengan adanya catatan-catatan di lapangan yang menunjukkan bahwa murid menunjukkan sikap saling memahami dan mengerti akan perasaan, pikiran serta kondisi orang lain (murid), bahkan murid menunjukkan sikap saling tolong menolong terhadap 
murid lain. Dengan demikian aktivitas pendidikan alam bebas atau outdoor education harus senantiasa dikembangkan secara terus menerus sehingga menjadi suatu sarana untuk mengembangkan kemampuan empati maupun aspek lain yang dapat diperoleh melalui outdoor education.

\section{SIMPULAN}

Kesimpulan dari hasil data yang telah diuraikan dalam penelitian ini adalah bahwa aktivitas luar ruangan berkontribusi pengaruh yang signifikan kepada empati murid. Berkaitan dari kesimpulan, kami memberikan rekomendasi beberapa saran berkaitan dengan peningkatan kemampuan empati murid melalui outdoor education. Sumbangsih saran ini juga disampaikan untuk pihak yang terkait seperti pada bidang pendidikan, yaitu: tenaga pendidik dan mungkin peneliti berikutnya. referensi dan saran dari kami diantaranya:

Untuk guru jika target pembelajaran ingin berinovasi berkaitan secara langsung bersama nilai sosial dan moral. Bagi yang ingin pendidikan alam bebas atau pendidikan luar ruangan idealnya menentukan rencana yang sesuai dengan situasi dan kondisi sekolah. Bagi guru yang ingin menerapkan pendidikan alam bebas sebaiknya menentukan rencana yang sesuai dengan kondisi murid dan sekolah.

Untuk peneliti berikutnya, dalam mengembangkan sikap empati melalui outdoor education, sangat memerlukan penelitian lebih lanjut yang bersifat pengembangan ataupun kedalaman kajian yang lebih mendalam. Perlu kajian-kajian lanjutan baik yang bersifat pengembangan maupun kedalamannya. Dengan demikian kami sampaikan kelemahan penelitian yang kami lakukan salah satu diantaranya kajian ini hanya dibatasi pada ranah sikap saja dengan demikian perlu kajian lanjutkan kepada kajian penelitian yang mengkaji kognitif atau psikomotor sehingga lebih komprehensif. Penelitian yang dilakukan ini, tanpa membedakan murid laki-laki dan perempuan. Maka masih perlu untuk dilaksanakan kajian penelitian dengan menggunakan sampel yang berbeda berdasarkan jenis kelamin laki-laki dan perempuan. Populasi dan sampel penelitian ini masih tingkatan SMP, maka masih ada kekosongan atau gap untuk dilaksanakan penelitian di kelas jenjang pendidikan lebih atas dan di tingkat pendidikan lebih bawah. 


\section{DAFTAR RUJUKAN}

Aartun, I., Walseth, K., Standal, Ø. F., \& Kirk, D. (2020). Pedagogies Of Embodiment In Physical Education-A Literature Review. Sport, Education And Society, 1-13. Https://Doi.Org/10.1080/13573322.2020.1821182

Ali Maksum. (2012). Metodologi Penelitian Dalam Olahraga. Surabaya: Unesapers.

Asep Ramdan Afriyuandi. (2014). Pengaruh Outdoor Education Berlandaskan Experimental Learning

Http://Repository.Upi.Edu/16457/

Bartelds, H., Savenije, G. M., \& Van Boxtel, C. (2020). Students' And Teachers' Beliefs About Historical Empathy In Secondary History Education. Theory And Research In Social Education, 1-23. Https://Doi.Org/10.1080/00933104.2020.1808131

Blakemore, T., \& Agllias, K. (2020). Social Media, Empathy And Interpersonal Skills: Social Work Students' Reflections In The Digital Era. Social Work Education, $39(2)$, 200-213. Https://Doi.Org/10.1080/02615479.2019.1619683

Wallen, N. E., \& Fraenkel, J. R. (2011). Educational Research: A Guide to the Process (2nd ed.). Taylor \&Francis e-Library.

Kardjono, J. (2014). (2014). Pendidikan Tabiat Hikmah Pesona Alam Bebas. Bandung: CV. Bintang Warliartika

Kim, K. J. (2020). Project-Based Learning Approach To Increase Medical Student Empathy. Medical Education Online, 25(1). Https://Doi.Org/10.1080/10872981.2020.1742965

Lutfia, D. (2017). Pengaruh outbound terhadap kecerdasan Moral anak sekolah dasar. Jurnal RAP (Riset Aktual Psikologi Universitas Negeri Padang), 5(2), 125-135.

Meyers, S., Rowell, K., Wells, M., \& Smith, B. C. (2019). Teacher Empathy: A Model Of Empathy For Teaching For Student Success. College Teaching, 67(3), 160-168. Https://Doi.Org/10.1080/87567555.2019.1579699

Nugroho, A. (2015). Usai Dihina "Burik" Oleh Teman, Kepala Siswi SD Di Bekasi Diduduki. Merdeka.Com.

Price, A. (2019). Using Outdoor Learning To Augment Social And Emotional Learning (SEL) Skills In Young People With Social, Emotional And Behavioural Difficulties (SEBD). Journal Of Adventure Education And Outdoor Learning, 19(4), 315-328. Https://Doi.Org/10.1080/14729679.2018.1548362 
Purnamasari, I. (2019). Pengaruh Latihan Relaksasi Otot Dengan Metode Progresif Dan Autogenik Terhadap Pemulihan Atlet Judo. 1-11.

Rahman, H. A. (2019). The Effect Of Outdoor Education On Students' Cohesiveness And Communication. April, 598-601. Https://Doi.Org/10.5220/0007066305980601

Sugiyono. (2011). Metode Penelitian Pendiikan (Pendekatan Kuantitatif, Kuantitatif, Kualitatif, Dan R\&D).Bandung: CV Alfabeta

Wahyu Sikumbang. (2015). Kasus Murid SD Di Pukuli Temannya Berujung Damai. Sindonews.Com.

Wang, J. C. K., Liu, W. C., \& Kahlid, A. (2006). Effects Of A Five-Day Outward Bound Course On Female Students In Singapore. Australian Journal Of Outdoor Education,. Http://Hdl.Handle.Net/10497/14650

Wijayanti, K. E. (2017). Implementasi Pendidikan Luar Sekolah (Outdoor Education) Terhadap Pembentukan Karakter Siswa Sekolah Dasar. Jurnal Pendidikan Jasmani Dan Olahraga, 2(1), 48. Https://Doi.Org/10.17509/Jpjo.V2i1.6400

Yulingga Nanda Hanief, S. (2015). Membentuk Gerak Dasar Pada Siswa Sekolah Dasar Melalui Permainan Tradisional. Jurnal Sportif: Jurnal Penelitian Pembelajaran, 1(1), 60-73. 